\title{
Post-antibiotic era is a worldwide challenge for health care: what to do?
}

\section{Letter to Editor}

In this $21^{\text {st }}$ century, antibiotics are almost worn out due to global antibiotic resistance scenario. It has become a worldwide concern to cope with the existing situation, where, even last resorts of antibiotics are not effective against common infections. After the discovery of New-Delhi Metallo $\beta$-lactamase- 1 (NDM-1) and its variants, evolving mutants, it is becoming difficult to use any $\beta$-lactam antibiotics, even carbapenems. Moreover, the use of colistin/polymyxin was one of the optimism to control such infections but MCR-1 discovery has turned down that prospect. Antibiotic resistance has now been recognized as serious global menace of 21st century to the mankind. Therefore, WHO has declared it as the priority research area and a "Global Action plan on antibiotic resistance" has already been launched to prevent this disaster taking to pre-antibiotic era.

In this desperate situation, a smart idea is

\section{References}

1. Hasan S, Ali SZ, Khan AU. Novel combinations of antibiotics to inhibit extended-spectrum $\beta$ lactamase and metallo- $\beta$-lactamase producers in vitro: a synergistic approach. Future Microbiol. 8:939-44 (2013).

2. Maryam L, Khan AU.A Mechanism of Synergistic Effect of Streptomycin and Cefotaxime on to make use of the existing resources in order to combat with this catastrophe. Hence, my research group has proposed two approaches which have already been experimentally proved and published, in vitro. First, an approach of synergism, use of combination antibiotics against strains of multi-antibiotic resistant bacteria. We have shown effective use of cefoxitin in combination with streptomycin and cefotaxime against multidrug resistant strains of bacteria, including NDM1 producing bacteria [1]. We have also described a possible mechanism of synergism [2]. Another novel initiative is photodynamic therapy, using nontoxic photosensitizers against bacteria. This has exclusively nonspecific action through generation of free radicals, damaging bacterial cells without effecting human system [3].

I am sure this write up would definitely help health workers as well as for those, seeking health.

CTX-M-15 Type $\beta$-lactamase Producing Strain of E. cloacae: A First Report. Front Microbiol. 7:2007 (2016).

3. Misba L, Zaidi S, Khan AU. A comparison of antibacterial and antibiofilm efficacy of phenothiazinium dyes between Gram positive and Gram negative bacterial biofilm. Photodiagnosis Photodyn Ther. 16: 30242-30243 (2017).

\section{Asad U Khan*}

Medical Microbiology and Molecular Biology Laboratory, Interdisciplinary Biotechnology Unit, A.M.U, Aligarh 202002 India

*Author for correspondence: asad.k@rediffmail.com Submitted Date: 12-May-2017 Accepted Date: 16-May-2017 Published Date: 19-May-2017 